\title{
Modeling Research Topics for Artificial Intelligence Applications in Medicine: Latent Dirichlet Allocation Application Study
}

Bach Xuan Tran ${ }^{1,2}$, PhD; Son Nghiem ${ }^{3}, \mathrm{PhD}$; Oz Sahin ${ }^{4}, \mathrm{PhD}$; Tuan Manh Vu ${ }^{5}$ PhD, MD; Giang Hai Ha ${ }^{6}, \mathrm{MSc}$; Giang Thu Vu ${ }^{7}$, MSc; Hai Quang Pham ${ }^{6}, \mathrm{MD}$; Hoa Thi Do ${ }^{8}$, PhD; Carl A Latkin ${ }^{2}$, PhD; Wilson Tam ${ }^{9}$, PhD; Cyrus $\mathrm{S} \mathrm{H} \mathrm{Ho}^{10}$, MBBS; Roger C M Ho ${ }^{11,12,13}$, MBBS

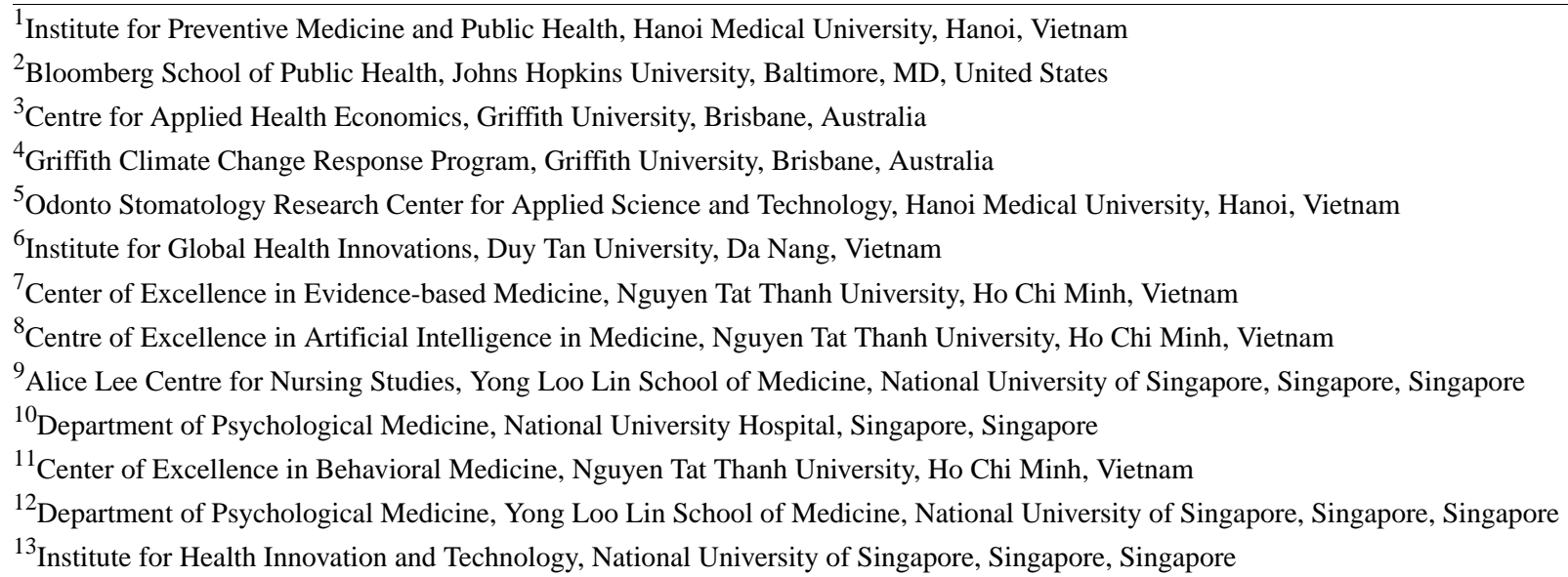

Corresponding Author:

Bach Xuan Tran, PhD

Institute for Preventive Medicine and Public Health

Hanoi Medical University

No 1 Ton That Tung Street

Hanoi, 100000

Vietnam

Phone: 84982228662

Email: bach.ipmph@gmail.com

\section{Abstract}

Background: Artificial intelligence (AI)-based technologies develop rapidly and have myriad applications in medicine and health care. However, there is a lack of comprehensive reporting on the productivity, workflow, topics, and research landscape of $\mathrm{AI}$ in this field.

Objective: This study aimed to evaluate the global development of scientific publications and constructed interdisciplinary research topics on the theory and practice of AI in medicine from 1977 to 2018.

Methods: We obtained bibliographic data and abstract contents of publications published between 1977 and 2018 from the Web of Science database. A total of 27,451 eligible articles were analyzed. Research topics were classified by latent Dirichlet allocation, and principal component analysis was used to identify the construct of the research landscape.

Results: The applications of AI have mainly impacted clinical settings (enhanced prognosis and diagnosis, robot-assisted surgery, and rehabilitation), data science and precision medicine (collecting individual data for precision medicine), and policy making (raising ethical and legal issues, especially regarding privacy and confidentiality of data). However, AI applications have not been commonly used in resource-poor settings due to the limit in infrastructure and human resources.

Conclusions: The application of AI in medicine has grown rapidly and focuses on three leading platforms: clinical practices, clinical material, and policies. AI might be one of the methods to narrow down the inequality in health care and medicine between developing and developed countries. Technology transfer and support from developed countries are essential measures for the advancement of AI application in health care in developing countries. 
(J Med Internet Res 2019;21(11):e15511) doi: 10.2196/15511

\section{KEYWORDS}

artificial intelligence; applications; medicine; scientometric; bibliometric; latent Dirichlet allocation

\section{Introduction}

The first idea of a thinking machine was developed in 1945 when a system that could amplify human knowledge was described in Vannevar Bush's seminal work [1]. Five years later, Alan Turing mentioned a machine being able to imitate human action and gave chess playing as an example of actions that a computer could do [2]. In 1956, artificial intelligence (AI) was first coined by John McCarthy in a Dartmouth conference [3]. Since then, there have been a few definitions of AI [4-6]. Although there is no consistency in these definitions, one common idea is that $\mathrm{AI}$ is an intelligent machine or a system, displaying intelligent behavior.

There are two schools of thought among the AI community: conventional artificial intelligence and computational intelligence [7]. Conventional AI includes machine learning and statistical analysis, while the neural network and fuzzy system belong to computational intelligence $[7,8]$. Other applications of AI include expert system, automation, and artificial creativity [9]. Expert system and machine learning are two of the most popular applications of AI. The expert system emulates the decision-making ability of humans in a field, while machine learning is a computer program that has the ability to learn from experience. In addition, robotics, a science of dealing with designing and operating robots, with the application of AI, has created robots with improved quality in sensing, vision, and self-awareness [10].

With continuous development and challenges to overcome, AI has been applied in various fields of society such as game playing [11], computer vision [12], speech recognition [13], and expert system in health care [14] and economics [15]. In particular, the contribution of $\mathrm{AI}$ in medicine and health care has brought about changes in not only the health system but also patients. The earliest application of $\mathrm{AI}$ in medicine dates to 1964, with the corporation of scientists from multidisciplinary research fields for the DENDRAL project [16]. The success of this scientific reasoning is one reason for the explosive spread of AI in biomedicine in the 1970s [17]. Another early application of AI to health care was medical diagnostic decision support systems, which appeared in 1954 [18]. Over the last 60 years, there has been a huge wave of AI technologies in health care. This change is reflected by not only the rapid increase in the number of papers in $\mathrm{AI}$ in medicine and health care, but also the appearance of AI in various medical fields [19]. Several AI techniques such as robotics, deep learning, support vector machines, or machine learning have been widely applied in the medical diagnostic system, treatment, and rehabilitation [20-22]. Some scientific publications have shown the effectiveness of $\mathrm{AI}$ in medicine and health care. In medical diagnosis, AI has been proved to be effective in improving the diagnostic accuracy for physical diseases [23-25]. The expert system has been used for diagnosis of diseases such as heart disease [26] and diabetes [27] and has proven to be useful for diagnosis and basic treatment advice [27]. For mental illness, AI may be useful for psychiatric consultations. Machine learning has been applied in a predictive model, which could identify patients with symptoms of schizophrenia and attempting to commit suicide with $74 \%$ and $80 \%-90 \%$ accuracy, respectively [28,29]. In terms of treatment, most robots assist clinicians in surgery but do not independently perform operations [30].

Due to the variety of AI applications in medicine and health care, there is a need to understand the current states of AI applications, major topics, and the research area of AI in medicine and health care and to identify research gaps. This study attempted to contribute to this understanding by analyzing the context and landscape of research topics [19]. Compared with previous scientometrics research, this study is global and assessed a wide range of AI utilities in medicine and health care $[31,32]$. Our study used scientific publications downloaded from the Web of Science to model the change and achievement of research topics and landscape in AI applications in health and medicine documents.

Thus, this study evaluated the global development of scientific publications from 1977 to 2018 and characterized research landscapes and constructs of disciplines applied to AI in medicine and health care. By decoding these patterns, we can effectively explore the changes in the growth of publications and may therefore provide better information for other researchers and policymakers in priority settings and evaluation.

\section{Methods}

\section{Search Strategies and Data Source}

The full strategy of our study has been presented elsewhere [33] (Multimedia Appendix 1). Data were retrieved from the Web of Sciences database provided by Thomson Reuters Institute for Scientific Information. We chose this database because of its outstanding advantages over other databases such as Scopus or PubMed: It contains bibliographic data since 1900, has a higher scientific journal impact, has more indexes, and is better in representing metadata [34].

\section{Data Download}

The data under .txt format, including the paper information (publication name, authors, journals' name, year of publication, keywords, author affiliations, total citation, subject research, and abstracts), were downloaded from Web of Science. Two researchers worked independently to simultaneously download the data. Subsequently, we filtered all downloaded data by excluding papers that were published in 2019, not original articles and reviews, written by an anonymous author, and not in English (Multimedia Appendix 2). Any conflict was resolved by discussion. All the data were merged and analyzed by STATA software (STATACorp LLC, College Station, TX). 


\section{Data Analysis}

We analyzed data based on the characteristic of publication (total papers, publication years, and number of papers by countries), research areas, abstracts (terms and contents of the abstract), citations, and usages (number of downloads). Subsequently, we used STATA software to perform a content analysis of the abstracts. We applied principal component analysis to identify the landscape of AI in medicine and health care. The Jaccard similarity index was utilized to identify research topics or terms most frequently co-occurring with each other. We applied a topic modeling technique for data mining and determining relationships among text documents. Specifically, we chose latent Dirichlet allocation (LDA), which is one of the most popular methods in this field for further analysis. LDA was a helpful technique to classify papers into similar topics [35-39]. It helps recognize the structure of research development, current trends, and interdisciplinary landscapes of research in AI applied to medicine. Using LDA, we classified text in each abstract to a topic where Dirichlet is used as a distribution over discrete distribution; each component in a random vector is the probability of drawing the words/texts associated with that component. Principle component analysis (PCA) was used to classify the research disciplines into corresponding groups.

Thus, by applying LDA, we could obtain an in-depth view of the trends of AI in health care and annotate the documents' topic to discover hidden themes [40]. Additionally, the landscape analysis addressed the relationship between research disciplinaries and showed how research areas in medicine and health care changed due to AI. The summary of analytical techniques for each data types is presented in Table 1 .

Table 1. Summary of analytical techniques for each data types.

\begin{tabular}{|c|c|c|}
\hline Type of data and unit of analysis & Analytical methods & Presentations of results \\
\hline \multicolumn{3}{|l|}{ Abstracts } \\
\hline Words & Frequency of co-occurrence & - Number of papers by countries in abstracts \\
\hline Papers & Latent Dirichlet allocation & - Ten classifications of research topics \\
\hline \multicolumn{3}{|c|}{ Web of Science classification of research areas } \\
\hline Web of Science research areas & Coincidence analysis & $\begin{array}{l}\text { - Dendrogram of research disciplines (Web of Science classification) } \\
\text { - The Web of Science research areas constructing Latent Dirichlet al- } \\
\text { location research topics }\end{array}$ \\
\hline
\end{tabular}

\section{Results}

\section{Number of Published Items and Publication Trend}

As seen in Table 1, the number of AI publications increased rapidly during the past 40 years. Notably, most of the publications $(23,216$ papers, $84.6 \%)$ were published during the last 10 years, and $60.6 \%$ of the total citation belonged to this period. The usage of papers was counted by the number of downloads. The mean use rate (download rate) within the last 6 months, of papers published in the year 2018 was three times higher than that of papers published in the previous years. The mean use rate within the last 5 years reached its peak in 2013 and decreased from 2012.

We analyzed the frequency of a country where the study was conducted, which was mentioned in the abstract (Table 2). Among 50 countries, the United States appeared the most (1867 times, 40.4\%). Notably, only four African countries (Egypt,
Niger, Kenya, and Nigeria) were mentioned in the abstracts. In addition, 13 Asian countries contributed to this list, and two Asian leaders of AI technologies-China (including Taiwan and Hong Kong) and India - accounted for $9.8 \%$ and $4.32 \%$ of the total papers, respectively.

\section{Research Landscapes}

Table 3 presents the scientific research topics constructed by LDA. By analyzing the most frequent words and titles, we could manually annotate the label of each topic. Robotics, which most mentioned the 10 topics and branches of AI (topic 1, topic 6, and topic 9), has supported surgery and treatment. AI types were applied the most in the diagnosis and prediction (topic 2, topic 5 , and topic 7). Based on development visualization, there was a growing trend in some of the 10 topics, with different rates. The number of papers related to topic 1 was highest and increased gradually but with a slower rate in recent years. Moreover, the number of papers in topic 2 and topic 3 increased at a higher rate than that of papers in other topics (Figure 1). 
Table 2. General characteristics of publications.

\begin{tabular}{|c|c|c|c|c|c|c|c|}
\hline Year published & $\begin{array}{l}\text { Total number of } \\
\text { papers }\end{array}$ & $\begin{array}{l}\text { Total number of } \\
\text { citations }\end{array}$ & $\begin{array}{l}\text { Mean citation } \\
\text { rate per year }\end{array}$ & $\begin{array}{l}\text { Total usage in } \\
\text { last } 6 \text { months }\end{array}$ & $\begin{array}{l}\text { Total usage in } \\
\text { last } 5 \text { years }\end{array}$ & $\begin{array}{l}\text { Mean use rate } \\
\text { in last } 6 \text { months }\end{array}$ & $\begin{array}{l}\text { Mean use rate } \\
\text { in last } 5 \text { years }\end{array}$ \\
\hline 2018 & 5619 & 7084 & 1.26 & 35,677 & 57,370 & 6.35 & 2.04 \\
\hline 2017 & 3919 & 19,639 & 2.51 & 11,320 & 56,890 & 2.89 & 2.90 \\
\hline 2016 & 2969 & 27,636 & 3.10 & 6684 & 55,729 & 2.25 & 3.75 \\
\hline 2015 & 2416 & 31,168 & 3.23 & 4,193 & 46,820 & 1.74 & 3.88 \\
\hline 2014 & 1990 & 30,523 & 3.07 & 2473 & 35,563 & 1.24 & 3.57 \\
\hline 2013 & 1839 & 35,259 & 3.20 & 2010 & 37,934 & 1.09 & 4.13 \\
\hline 2012 & 1385 & 30,130 & 3.11 & 1114 & 19,950 & 0.80 & 2.88 \\
\hline 2011 & 1189 & 37,313 & 3.92 & 1379 & 18,603 & 1.16 & 3.13 \\
\hline 2010 & 1010 & 28,270 & 3.11 & 661 & 10,185 & 0.65 & 2.02 \\
\hline 2009 & 880 & 27,847 & 3.16 & 678 & 9607 & 0.77 & 2.18 \\
\hline 2008 & 718 & 26,865 & 3.40 & 530 & 6944 & 0.74 & 1.93 \\
\hline 2007 & 557 & 19,402 & 2.90 & 343 & 4575 & 0.62 & 1.64 \\
\hline 2006 & 479 & 24,213 & 3.89 & 375 & 4923 & 0.78 & 2.06 \\
\hline 2005 & 367 & 13,460 & 2.62 & 178 & 2473 & 0.49 & 1.35 \\
\hline 2004 & 350 & 16,294 & 3.10 & 216 & 3240 & 0.62 & 1.85 \\
\hline 2003 & 262 & 14,671 & 3.50 & 188 & 2465 & 0.72 & 1.88 \\
\hline 2002 & 195 & 14,143 & 4.27 & 157 & 2109 & 0.81 & 2.16 \\
\hline 2001 & 191 & 8852 & 2.57 & 117 & 1766 & 0.61 & 1.85 \\
\hline 2000 & 170 & 8056 & 2.49 & 87 & 1171 & 0.51 & 1.38 \\
\hline 1999 & 150 & 5517 & 1.84 & 61 & 678 & 0.41 & 0.90 \\
\hline 1998 & 163 & 4396 & 1.28 & 44 & 606 & 0.27 & 0.74 \\
\hline 1997 & 124 & 7179 & 2.63 & 89 & 877 & 0.72 & 1.41 \\
\hline 1996 & 114 & 3310 & 1.26 & 29 & 373 & 0.25 & 0.65 \\
\hline 1995 & 98 & 3182 & 1.35 & 38 & 334 & 0.39 & 0.68 \\
\hline 1994 & 100 & 3570 & 1.43 & 37 & 328 & 0.37 & 0.66 \\
\hline 1993 & 61 & 2238 & 1.41 & 29 & 222 & 0.48 & 0.73 \\
\hline 1992 & 62 & 1395 & 0.83 & 25 & 225 & 0.40 & 0.73 \\
\hline 1991 & 41 & 683 & 0.59 & 31 & 101 & 0.76 & 0.49 \\
\hline 1990 & 8 & 179 & 0.77 & 5 & 16 & 0.63 & 0.40 \\
\hline 1989 & 2 & 438 & 7.30 & 2 & 9 & 1.00 & 0.90 \\
\hline 1988 & 7 & 117 & 0.54 & 3 & 21 & 0.43 & 0.60 \\
\hline 1987 & 6 & 18 & 0.09 & 2 & 8 & 0.33 & 0.27 \\
\hline 1986 & 5 & 59 & 0.36 & 4 & 14 & 0.80 & 0.56 \\
\hline 1985 & 2 & 4 & 0.06 & 0 & 1 & 0.00 & 0.10 \\
\hline 1984 & 1 & 7 & 0.20 & 0 & 3 & 0.00 & 0.60 \\
\hline 1980 & 1 & 51 & 1.31 & 0 & 7 & 0.00 & 1.40 \\
\hline 1977 & 1 & 3 & 0.07 & 1 & 4 & 1.00 & 0.80 \\
\hline
\end{tabular}


Table 3. Number of papers by countries as study settings.

\begin{tabular}{|c|c|c|}
\hline Rank & Country settings & Frequency, n (\%) \\
\hline 1 & United States & $1867(40.4)$ \\
\hline 2 & Ireland & $332(7.2)$ \\
\hline 3 & Taiwan & $215(4.7)$ \\
\hline 4 & China & $208(4.5)$ \\
\hline 5 & United Kingdom & $194(4.2)$ \\
\hline 6 & India & $181(3.9)$ \\
\hline 7 & Japan & 164 (3.6) \\
\hline 8 & Australia & $141(3.1)$ \\
\hline 9 & Canada & $86(1.9)$ \\
\hline 10 & Iran & $83(1.8)$ \\
\hline 11 & Germany & $81(1.8)$ \\
\hline 12 & Italy & $74(1.6)$ \\
\hline 13 & Brazil & $58(1.3)$ \\
\hline 14 & Spain & $56(1.2)$ \\
\hline 15 & France & $55(1.2)$ \\
\hline 16 & Sweden & $43(0.9)$ \\
\hline 17 & Turkey & $43(0.9)$ \\
\hline 18 & Israel & $37(0.8)$ \\
\hline 19 & New Zealand & $33(0.7)$ \\
\hline 20 & Wallis and Futuna & $31(0.7)$ \\
\hline 21 & Hong Kong & $27(0.6)$ \\
\hline 22 & Mali & $27(0.6)$ \\
\hline 23 & Netherlands & $25(0.5)$ \\
\hline 24 & Poland & $25(0.5)$ \\
\hline 25 & Singapore & $23(0.5)$ \\
\hline 26 & Switzerland & $22(0.5)$ \\
\hline 27 & Greece & $21(0.5)$ \\
\hline 28 & South Africa & $20(0.4)$ \\
\hline 29 & Saudi Arabia & $19(0.4)$ \\
\hline 30 & Malaysia & $18(0.4)$ \\
\hline 31 & Egypt & $17(0.40$ \\
\hline 32 & Pakistan & $17(0.4)$ \\
\hline 33 & Denmark & $13(0.3)$ \\
\hline 34 & Belgium & $12(0.3)$ \\
\hline 35 & Georgia & $12(0.3)$ \\
\hline 36 & Niger & $12(0.3)$ \\
\hline 37 & Kenya & $11(0.2)$ \\
\hline 38 & Mexico & $11(0.2)$ \\
\hline 39 & Nigeria & $11(0.2)$ \\
\hline 40 & Austria & $10(0.2)$ \\
\hline 41 & Finland & $10(0.2)$ \\
\hline 42 & Chile & $9(0.2)$ \\
\hline
\end{tabular}




\begin{tabular}{lll}
\hline Rank & Country settings & Frequency, $\mathrm{n}(\%)$ \\
\hline 43 & Norway & $9(0.2)$ \\
44 & Portugal & $9(0.2)$ \\
45 & Thailand & $9(0.2)$ \\
46 & United Arab Emirates & $9(0.2)$ \\
47 & Colombia & $8(0.2)$ \\
48 & Jordan & $8(0.2)$ \\
49 & Serbia & $8(0.2)$ \\
50 & Czech & $7(0.2)$ \\
\hline
\end{tabular}

Figure 1. Changes in the applications of artificial intelligence to health and medicine in the past 10 years.

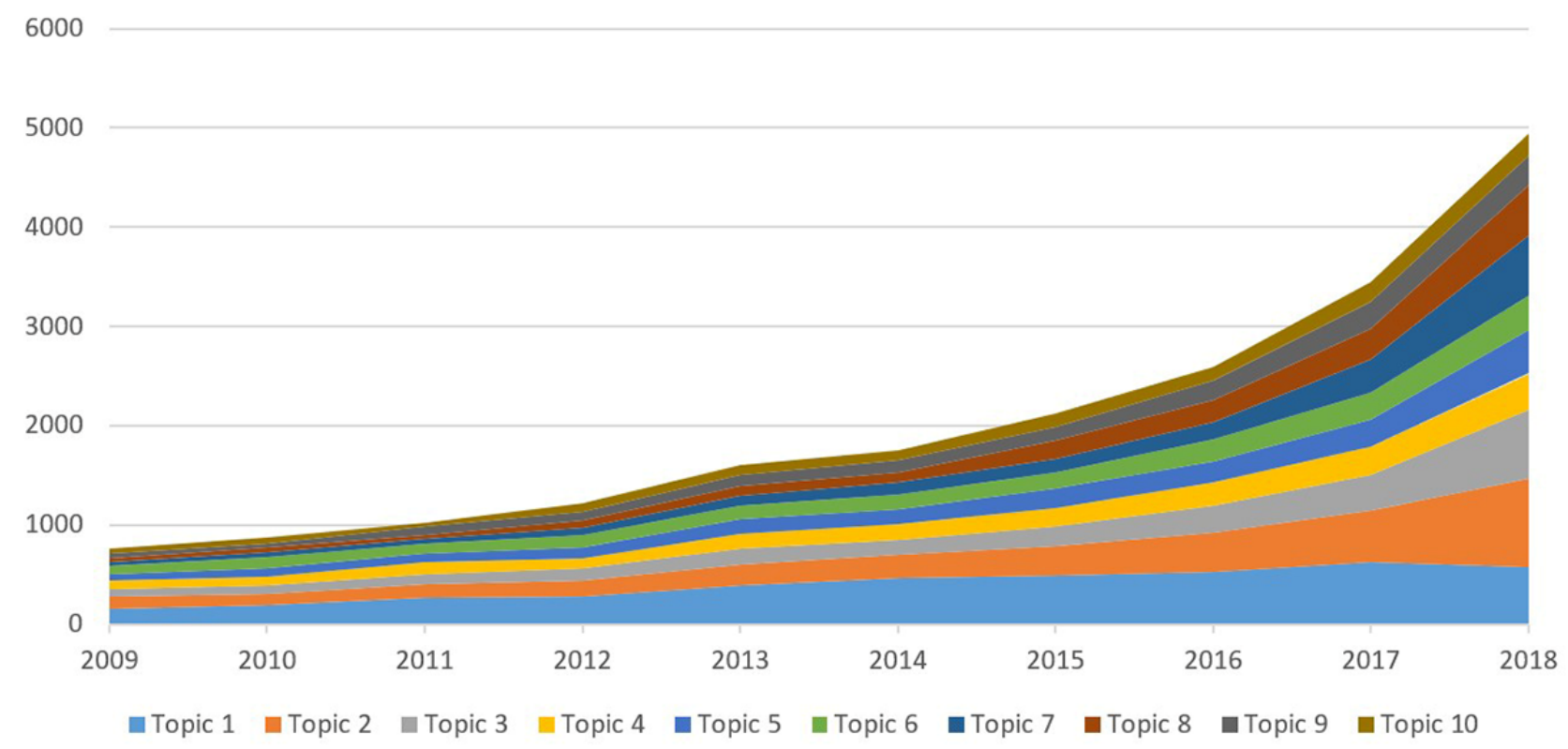

Based on the classification of research areas in the Web of Science, we identified the dendrograms for the areas (Figure 2). The dendrogram includes the clades and leaves. The clade is the branch, and each clade includes one or more research areas. The horizontal axis shows the distance or dissimilarity between research areas. Each joining (fusion) of two clusters is represented on the diagram by the splitting of a vertical line into two vertical lines. The vertical position of the split, shown by a short bar, gives the distance (dissimilarity) between the

two research areas. It shows that the AI applications focused on seven following research areas: surgery, robotics, and noncommunicable diseases (hepatocardiac disorders or cancer); neurosciences and psychiatry; the application of electronic health (telecommunication); chemical sciences; nanoscience; electrochemistry; and medical informatics and biotechnology. It seems that AI in medicine was assigned mainly to the disciplines diseases and treatment (surgery or robotics application). 
Figure 2. Dendrogram of coincidence of research areas using the Web of Science classifications.

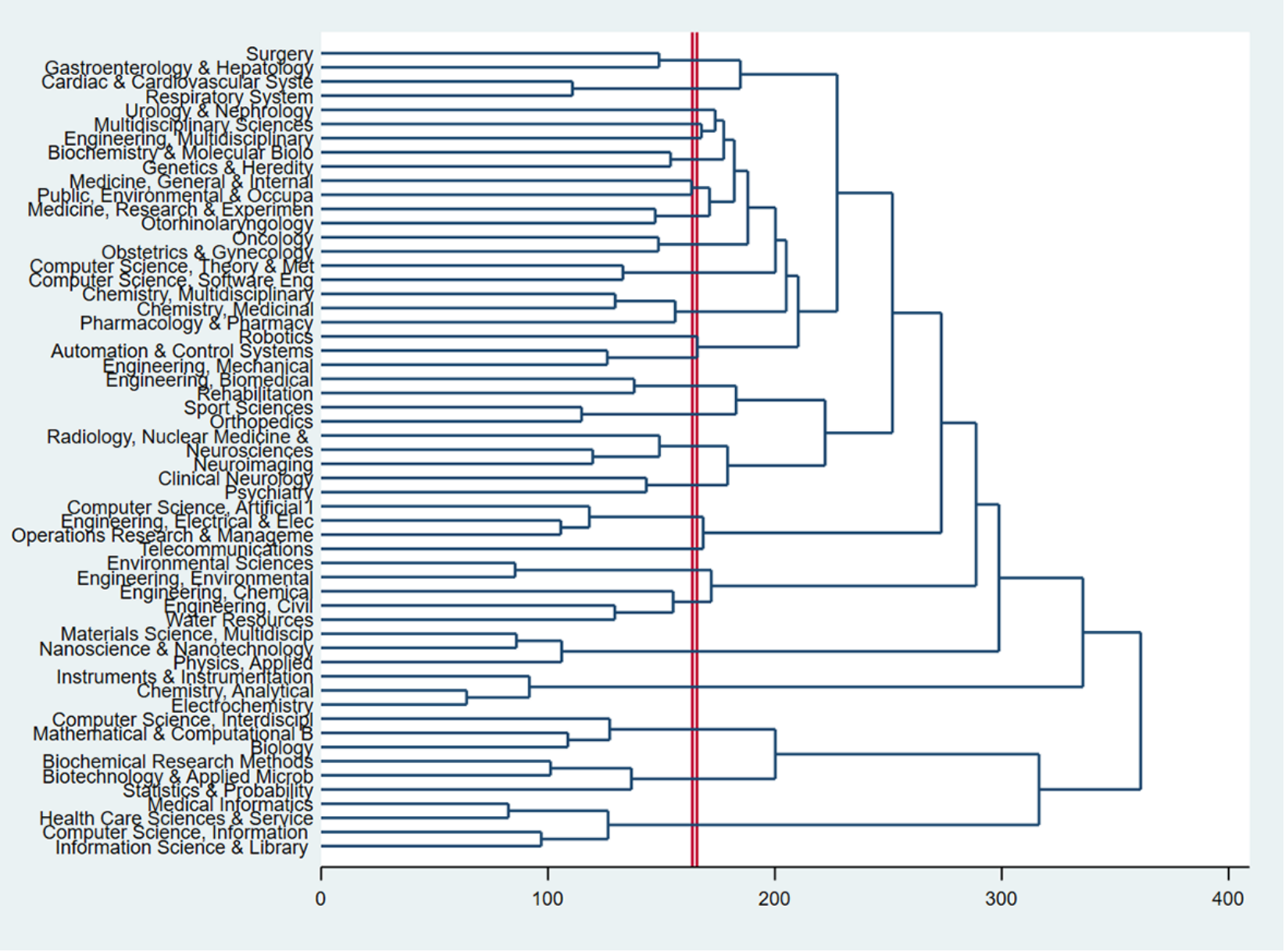

We applied PCA to identify the landscape of AI in medicine and health care (Figure 3). Based on the size of the node, most papers belonged to the following research categories: clinical: surgery, radiology, and nuclear medicine; technology: biomedical, robotics, computer science, medical informatics; and diseases: oncology, general and internal medicine and noncommunicable diseases. As shown in Figure 2, a strong relationship among the applications of AI in treatment, diseases, and medical informatics shows that AI assisted surgeons, especially in some diseases for which surgery is key in treatment or diagnosis, such as cancer or cardiovascular diseases. The combination of information science, computer science, and health care, called health informatics, has created a wide range of applications, from cell level to population level [41]. Collision of several computer science-related fields and medical fields created a multidisciplinary science, which has led to better chances of providing the best treatment to patients. Additionally, the development of computer sciences has contributed to the advancement of AI in pharmacy, biotechnology, and chemistry in areas such as drug discovery, drug identification and validation, and drug trials.

We compared ten research topics by LDA (Table 4) with Web of Science research areas (Multimedia Appendices 3-5) to identify the consistency of research disciplinaries of AI in medicine and health care. Computer science and its related fields appeared the most (eight topics). The major application of computer science has been in medical fields: from cells (gene microbiology information, topic 5), disease (oncology, cardiovascular, topic 7), and diagnosis and treatment (topic 1, topic 6, and topic 9) to health policy (topic 3). Additionally, AI types were used the most in medicine and health care, including expert systems, artificial neural networks, machine learning, and natural language processing. Robot and surgery were two applications mentioned the most in topic 1 , topic 6 , and topic 9 . Robotic-assisted procedures were used for cancer surgery and cardiovascular diseases. Robot-assisted therapy was used in treating sports concussion or neurorehabilitation (topic 9). 
Figure 3. Landscapes of artificial intelligence in medicine by Web of Science categories. PCA: principal component analysis.

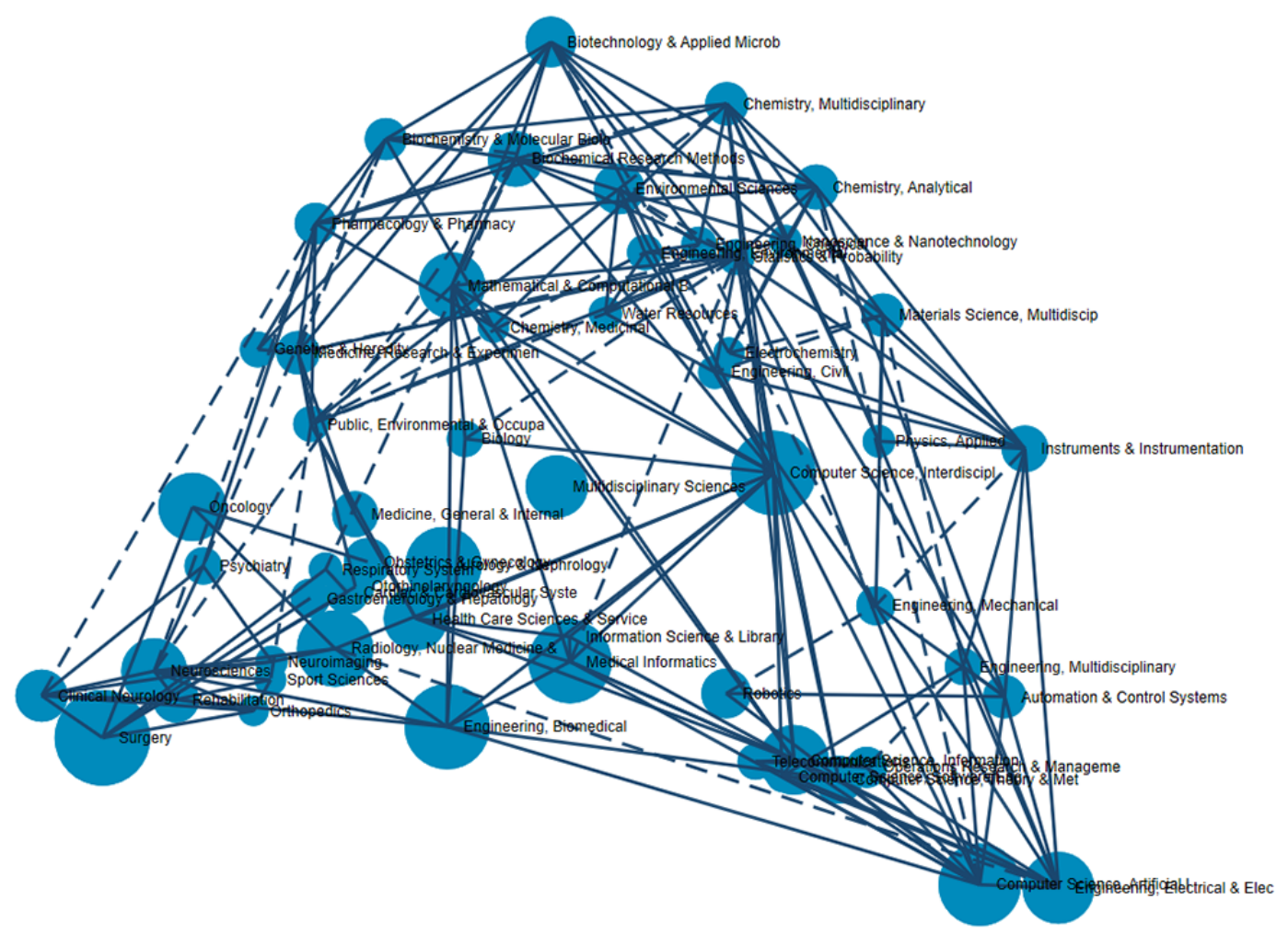

PCA coordinates

Table 4. Ten research topics classified by latent Dirichlet allocation.

\begin{tabular}{lll}
\hline Latent Dirichlet allocation topics & Frequency, $\mathrm{n}(\%)$ & Topic name \\
\hline Topic 1 & $4,3524,4352(18.1)$ & Comparative evaluation of robot-assisted surgery \\
Topic 2 & $3662(15.2)$ & Expert system for diseases diagnosis and prediction \\
Topic 3 & $2839(11.8)$ & Health system and policy on AIs ${ }^{\mathrm{a}}$ in medicine \\
Topic 4 & $2182(9.1)$ & Artificial neural networks in treatment selection \\
Topic 5 & $2089(8.7)$ & AI-based gene and protein analysis and prediction \\
Topic 6 & $2065(8.6)$ & Precision robotics and personalized medicine \\
Topic 7 & $2008(8.4)$ & Enhanced diagnosis and classification by AI-based images analysis \\
Topic 8 & $1922(8.0)$ & Using machine learning to predict risk, disease progression, and treatment \\
outcomes & Robot-assisted rehabilitation treatment \\
Topic 10 & $1564(6.5)$ & Natural language processing tools for biomedical texts and clinical notes \\
\hline
\end{tabular}

${ }^{\mathrm{a} A I}$ : artificial intelligence.

\section{Discussion}

\section{Principal Results}

By analyzing scientific research publications and modeling their research topics, we generally described the 42-year development and identified the trend of AI application in medicine and health care. The mean use rate related to the application of $\mathrm{AI}$ in medicine was the highest in the last 5 years and tended to reduce since 2012. This can be explained by the rapid development of technology and research [42]: Scientific papers published more than 5 years ago would not attract the attention of scientists. Therefore, dissemination efforts need to be taken into consideration by not only policy makers but also authors, to increase the influence and implement changes in practice settings [43]. In addition, the results show a rapid increase in 
research productivity and downloaded papers in the last 5 years. Its growth was contributed mostly by western countries, driven by the United States. Among 11 Asian countries in that list, China and India were two leaders in research on AI in medicine. The application of AI has benefitted the health care system in high-income countries. One study showed that the United States could save US \$5-\$8 billion per year with the application of information technology in health care [44]. Another recent analysis found that with the application of AI, we can save up to US $\$ 150$ billion in yearly health costs [45]. AI, however, has not been widely used in low-income countries. This could be due to the undeveloped infrastructure in the internet, technology, and health systems and a lack of highly qualified human resource. Regardless of the disadvantages, AI holds promise for changing health care services in low-income countries [46].

Based on the topics and research areas, we found that the application of AI in medicine and health care has been focused on robot support in surgery (topic 1) and rehabilitation (topic 9), AI in diagnosis and clinical decisions support (topic 2, topic 4 , topic 5 , topic 7 , topic 8 , and topic 10 ), and AI in health care system management (topic 3). First, for clinical treatment, our results confirm that medical robots and robot-assisted surgeries have been widely used $[47,48]$. AI has been widely applied in surgery due to its benefits for patients and medical professionals, such as increased accuracy, reduced operation time, minimized surgical trauma, and reduced length of recovery time for patients [49]. Second, AI methods such as machine learning and natural language process analyze complex medical data [20], decrease time spent finding relevant evidence, and reduce medical errors that improve the quality of diagnosis in medical health care [50]. Finally, AI will certainly be applied more in the health care system in the future owing to its advantages over the traditional decision-making process. On the other hand, the fact that users do not know how the results are analyzed by the "black box" algorithms, ethnic differences in validity of facial recognition technology for genetic diagnosis, medical and behavioral conditions [51,52], and ethnic bias in training data set [53] raise questions about product liability, privacy and data protection, and ethical and legal issues [51]. Thus, researchers have voiced their concern about legacy and ethical guidelines that are lagging behind the development of AI in health care and medicine [51].

\section{Future Implications}

Our findings have some implications for health research and policy. The quick development of AI applications in health and medicine requires some preparations. AI may change the relationship between caregivers and patients, as the direct interaction might reduce due to digital tools such as a free app in the patient's personal device, which could diagnose the disease in some cases or even lead to self-diagnosis via the Web [54]. Thus, it is necessary for all parties involved to ensure that, in the case of mental health diagnosis, for instance, subtle signs of mental illness would not be neglected [55]. In addition, standard guidelines or laws about collecting private information or application of AI in all health care sectors are urgently needed [56], as the application of AI in health care and medicine has potential threats to patients' privacy and safety. Finally, AI is transforming health care in resource-poor settings and reducing the gap between rural and urban areas [46]. In rural areas of developing countries, the shortage of medical doctors and trained nurses and the limitation of medical techniques and machines have reduced the quality of medical services [57]. In addition, it is difficult to attract skilled medical workers in rural areas due to the poor working environment and living conditions [58]. However, the development of AI applications can be a solution to these problems. For instance, the AI method (machine learning) proposed a model helping forecast dengue outbreaks in China [59]. In addition, AI has proven to be effective, with a high accuracy of breast cancer detection [60,61]. Moreover, AI can reduce medical costs in developing countries. For example, a highly effective AI method could provide an alternative to expensive diagnostic methods to classify acute leukemia [62]. However, absorptive capacity, local culture, legacy [63], and infrastructure (eg, electricity, internet, or financial source) should be carefully taken into consideration [64]. Notably, policy development for AI should be given more attention, since its failure has been recognized in developing countries such as Vietnam [65].

\section{Limitations}

Our study has several limitations worth noting. First, we choose only Web of Science as the database, which may not cover all the publications in the research fields. Second, only English articles and reviews were analyzed in this study. Finally, we applied LDA to model the topic research in title and abstracts, not the full text. However, two other methods (coincidence analysis and PCA) confirmed similar results about the connections of research topics. Thus, LDA could be considered a support method to reduce the workload in the screening step for future systematic reviews [66].

\section{Conclusions}

The application of AI in medicine has grown rapidly and focuses on three leading platforms: clinical practices, clinical material, and policies. AI might be one of the methods to reduce the inequality in health care and medicine between developing and developed countries. Technology transfer and support from developed countries, along with the internal efforts of poor-setting countries, help in the development of AI applications in health care and medicine.

\section{Conflicts of Interest}

None declared.

\section{Multimedia Appendix 1}

Search results (Web of Science). 


\section{Multimedia Appendix 2}

Selection of papers in the Web of Science database.

[PDF File (Adobe PDF File), 306 KB-Multimedia Appendix 2]

\section{Multimedia Appendix 3}

The Web of Science research areas constructing latent Dirichlet allocation research topics (topics 1-3).

[PDF File (Adobe PDF File), 25 KB-Multimedia Appendix 3]

\section{Multimedia Appendix 4}

The Web of Science research areas constructing latent Dirichlet allocation research topics (topics 4-6).

[PDF File (Adobe PDF File), 25 KB-Multimedia Appendix 4]

\section{Multimedia Appendix 5}

The Web of Science research areas constructing latent Dirichlet allocation research topics (topics 7-10).

[PDF File (Adobe PDF File), 28 KB-Multimedia Appendix 5]

\section{References}

1. Bush V. As we may think. Interactions $1945 ; 3(2): 35-46$. [doi: $10.1145 / 227181.227186]$

2. Turing A. Computing machinery and intelligence. Mind 1950;LIX(236):433-460. [doi: 10.1093/mind/LIX.236.433]

3. Nilsson NJ. Stanford University. 2011. Professor John McCarthy URL: https://cs.stanford.edu/memoriam/ professor-john-mccarthy [accessed 2019-04-16]

4. High-Level Expert Group on Artificial Intelligence. A definition of Artificial Intelligence: main capabilities and scientific disciplines. Brussels: European Commission; Apr 08, 2019.

5. Ramesh A, Kambhampati C, Monson J, Drew P. Artificial intelligence in medicine. Ann R Coll Surg Engl 2004 Sep 01;86(5):334-338. [doi: 10.1308/147870804290]

6. McCarthy J. Stanford University. 2007. What is AI?/Basic Questions URL: http://jmc.stanford.edu/artificial-intelligence/ what-is-ai/index.html [accessed 2019-04-16]

7. Das S, Dey A, Pal A, Roy N. Applications of Artificial Intelligence in Machine Learning: Review and Prospect. IJCA 2015 Apr 22;115(9):31-41. [doi: 10.5120/20182-2402]

8. Bittermann M. Design Computing and Cognition (DCC10). 2010. Artificial Intelligence (AI) versus Computational Intelligence (CI) for treatment of complexity in design Design Computing and Cognition URL: https://pdfs. semanticscholar.org/de17/414444750423573b60bfd206d0047a90c0fa.pdf [accessed 2019-09-06]

9. Singla J. The Diagnosis of Some Lung Diseases in a Prolog Expert System. IJCA 2013 Sep 18;78(15):37-40. [doi: 10.5120/13603-1435]

10. Perez J, Deligianni F, Ravi D, Yang GZ. Artificial intelligence and robotics. London: UK-RAS; 2018.

11. Harbing L. Harvard University. 2017. AI in Video Games: Toward a More Intelligent Game URL: http://sitn.hms.harvard.edu/ flash/2017/ai-video-games-toward-intelligent-game/ [accessed 2019-04-16]

12. Gao J, Yang Y, Lin P, Park DS. Computer Vision in Healthcare Applications. J Healthc Eng 2018;2018:5157020 [REEE Full text] [doi: 10.1155/2018/5157020] [Medline: 29686826]

13. Smadi TA, Al Issa HA, Trad E, Smadi KAA. Artificial Intelligence for Speech Recognition Based on Neural Networks. JSIP 2015;06(02):66-72. [doi: 10.4236/jsip.2015.62006]

14. McCauley N, Ala M. The use of expert systems in the healthcare industry. Information \& Management 1992 Apr;22(4):227-235 [FREE Full text] [doi: 10.1016/0378-7206(92)90025-b]

15. John McCarthy. 2018. What is AI?/Applications of AI URL: http://jmc.stanford.edu/artificial-intelligence/what-is-ai/ applications-of-ai.html [accessed 2019-04-16]

16. Lindsay R, Buchanan B, Feigenbaum E, Lederberg J. Applications of Artificial Intelligence for Organic Chemistry: The DENDRAL Project. New York, NY: McGraw-Hill; 1980.

17. Patel VL, Shortliffe EH, Stefanelli M, Szolovits P, Berthold MR, Bellazzi R, et al. The coming of age of artificial intelligence in medicine. Artif Intell Med 2009 May;46(1):5-17 [FREE Full text] [doi: 10.1016/j.artmed.2008.07.017] [Medline: $\underline{18790621]}$

18. Miller RA. Medical diagnostic decision support systems--past, present, and future: a threaded bibliography and brief commentary. J Am Med Inform Assoc 1994;1(1):8-27 [FREE Full text] [Medline: 7719792]

19. Tran B, Vu G, Ha G, Vuong Q, Ho M, Vuong T, et al. Global Evolution of Research in Artificial Intelligence in Health and Medicine: A Bibliometric Study. JCM 2019 Mar 14;8(3):360. [doi: 10.3390/jcm8030360]

20. Jiang F, Jiang Y, Zhi H, Dong Y, Li H, Ma S, et al. Artificial intelligence in healthcare: past, present and future. Stroke Vasc Neurol 2017 Dec;2(4):230-243 [FREE Full text] [doi: 10.1136/svn-2017-000101] [Medline: 29507784] 
21. Lundberg SM, Nair B, Vavilala MS, Horibe M, Eisses MJ, Adams T, et al. Explainable machine-learning predictions for the prevention of hypoxaemia during surgery. Nat Biomed Eng 2018 Oct;2(10):749-760. [doi: 10.1038/s41551-018-0304-0] [Medline: $\underline{31001455]}$

22. Son Y, Kim H, Kim E, Choi S, Lee S. Application of support vector machine for prediction of medication adherence in heart failure patients. Healthc Inform Res 2010 Dec;16(4):253-259 [FREE Full text] [doi: 10.4258/hir.2010.16.4.253] [Medline: 21818444]

23. Gargeya R, Leng T. Automated Identification of Diabetic Retinopathy Using Deep Learning. Ophthalmology 2017 Dec;124(7):962-969. [doi: 10.1016/j.ophtha.2017.02.008] [Medline: 28359545]

24. Long E, Lin H, Liu Z, Wu X, Wang L, Jiang J, et al. An artificial intelligence platform for the multihospital collaborative management of congenital cataracts. Nat Biomed Eng 2017 Jan 30;1(2). [doi: 10.1038/s41551-016-0024]

25. Esteva A, Kuprel B, Novoa RA, Ko J, Swetter SM, Blau HM, et al. Dermatologist-level classification of skin cancer with deep neural networks. Nature 2017 Dec 02;542(7639):115-118. [doi: 10.1038/nature21056] [Medline: 28117445]

26. Al-Shayea Q. Artificial Neural Networks in Medical Diagnosis. International Journal of Computer Science Issues 2011;8(2):150-154 [FREE Full text]

27. Zeki T, Malakooti M, Ataeipoor Y, Tabibi S. An Expert System for Diabetes Diagnosis. American Academic \& Scholarly Research Journal 2012;4(5):1-13 [FREE Full text]

28. Gheiratmand M, Rish I, Cecchi GA, Brown MRG, Greiner R, Polosecki PI, et al. Learning stable and predictive network-based patterns of schizophrenia and its clinical symptoms. NPJ Schizophr 2017 May 16;3(1):22. [doi: 10.1038/s41537-017-0022-8] [Medline: 28560268]

29. Just MA, Pan L, Cherkassky VL, McMakin DL, Cha C, Nock MK, et al. Machine learning of neural representations of suicide and emotion concepts identifies suicidal youth. Nat Hum Behav 2017 Oct 30;1(12):911-919. [doi: 10.1038/s41562-017-0234-y]

30. Loh E. Medicine and the rise of the robots: a qualitative review of recent advances of artificial intelligence in health. Leader 2018 Jun 01;2(2):59-63. [doi: 10.1136/leader-2018-000071]

31. Darko A, Chan A, Huo X, Owusu-Manu D. A scientometric analysis and visualization of global green building research. Building and Environment 2019 Feb;149:501-511 [FREE Full text] [doi: 10.1016/j.buildenv.2018.12.059]

32. Ma GP. The Development and Research Trends of Artificial Intelligence in Neuroscience: A Scientometric Analysis in CiteSpace. AMR 2013 Jul;718-720:2068-2073. [doi: 10.4028/www.scientific.net/amr.718-720.2068]

33. Tran BX, Vu GT, Ha GH, Vuong Q, Ho M, Vuong T, et al. Global Evolution of Research in Artificial Intelligence in Health and Medicine: A Bibliometric Study. J Clin Med 2019 Mar 14;8(3) [FREE Full text] [doi: 10.3390/jcm8030360] [Medline: 30875745]

34. Chadegani AA, Salehi H, Yunus MM, Farhadi H, Fooladi M, Farhadi M, et al. A Comparison between Two Main Academic Literature Collections: Web of Science and Scopus Databases. ASS 2013 Apr 27;9(5). [doi: 10.5539/ass.v9n5p18]

35. Li Y, Rapkin B, Atkinson TM, Schofield E, Bochner BH. Leveraging Latent Dirichlet Allocation in processing free-text personal goals among patients undergoing bladder cancer surgery. Qual Life Res 2019 Feb 23:23 [FREE Full text] [doi: 10.1007/s11136-019-02132-w] [Medline: $\underline{30798421]}$

36. Valle D, Albuquerque P, Zhao Q, Barberan A, Fletcher RJ. Extending the Latent Dirichlet Allocation model to presence/absence data: A case study on North American breeding birds and biogeographical shifts expected from climate change. Glob Chang Biol 2018 Dec;24(11):5560-5572 [FREE Full text] [doi: 10.1111/gcb.14412] [Medline: $\underline{30058746]}$

37. Chen C, Zare A, Trinh HN, Omotara GO, Cobb JT, Lagaunne TA. Partial Membership Latent Dirichlet Allocation for Soft Image Segmentation. IEEE Trans Image Process 2017 Dec;26(12):5590-5602. [doi: 10.1109/TIP.2017.2736419] [Medline: 28792897]

38. Lu H, Wei C, Hsiao F. Modeling healthcare data using multiple-channel latent Dirichlet allocation. J Biomed Inform 2016 Apr;60:210-223 [FREE Full text] [doi: 10.1016/j.jbi.2016.02.003] [Medline: 26898516]

39. Gross A, Murthy D. Modeling virtual organizations with Latent Dirichlet Allocation: a case for natural language processing. Neural Netw 2014 Oct;58:38-49. [doi: 10.1016/j.neunet.2014.05.008] [Medline: 24930023]

40. Tong Z, Zhang H. A Document Exploring System on LDA Topic Model for Wikipedia Articles. IJMA 2016 Aug 30;8(3/4):01-13. [doi: 10.5121/ijma.2016.8401]

41. Kukafka R, O'Carroll PW, Gerberding JL, Shortliffe EH, Aliferis C, Lumpkin JR, et al. Issues and opportunities in public health informatics: a panel discussion. J Public Health Manag Pract 2001 Nov;7(6):31-42. [Medline: 11710167 ]

42. SFR-IA Group, CERF, French Radiology Community. Artificial intelligence and medical imaging 2018: French Radiology Community white paper. Diagn Interv Imaging 2018 Nov;99(11):727-742. [doi: 10.1016/j.diii.2018.10.003] [Medline: $\underline{30470627]}$

43. Brownson R, Eyler A, Harris J, Moore J, Tabak R. Getting the Word Out. Journal of Public Health Management and Practice 2018;24(2):102-111. [doi: 10.1097/phh.0000000000000673]

44. Neumann PJ, Parente ST, Paramore LC. Potential savings from using information technology applications in health care in the United States. Int J Technol Assess Health Care 1996;12(3):425-435. [Medline: $\underline{840663]}$

45. Collier M, Fu R, Yin L. Accenture. 2017. Artifcial intelligence: healthcare's new nervous system URL: https://www. accenture.com/au-en/insight-artificial-intelligence-healthcare [accessed 2019-04-16] 
46. Wahl B, Cossy-Gantner A, Germann S, Schwalbe NR. Artificial intelligence (AI) and global health: how can AI contribute to health in resource-poor settings? BMJ Glob Health 2018 Aug 29;3(4):e000798. [doi: 10.1136/bmjgh-2018-000798] [Medline: $\underline{30233828}$ ]

47. Leung T, Vyas D. Robotic Surgery: Applications. Am J Robot Surg 2014 Jun 01;1(1):1-64 [FREE Full text] [Medline: 26501128]

48. Nishimura K. Current status of robotic surgery in Japan. Korean J Urol 2015 Mar;56(3):170-178 [FREE Full text] [doi: 10.4111/kju.2015.56.3.170] [Medline: 25763120]

49. Kose E, Ozturk NN, Karahan SR. Artificial Intelligence in Surgery. Eur Arch Med Res 2018 Dec 26;34(Suppl 1):4-6. [doi: 10.5152/eamr.2018.43043]

50. Walczak S. The Role of Artificial Intelligence in Clinical Decision Support Systems and a Classification Framework. International Journal of Computers in Clinical Practice 2018:31-47. [doi: 10.4018/IJCCP.2018070103]

51. Rigby M. Ethical Dimensions of Using Artificial Intelligence in Health Care. AMA Journal of Ethics 2019;21(2):121-124. [doi: 10.1001/amajethics.2019.121]

52. Martinez-Martin N. What Are Important Ethical Implications of Using Facial Recognition Technology in Health Care? AMA J Ethics 2019 Mar 01;21(2):E180-E187 [FREE Full text] [doi: 10.1001/amajethics.2019.180] [Medline: 30794128$]$

53. Dolgin E. AI face-scanning app spots signs of rare genetic disorders. Nature 2019 Jan 7:A. [doi: 10.1038/d41586-019-00027-x]

54. White RW, Horvitz E. Web to world: predicting transitions from self-diagnosis to the pursuit of local medical assistance in web search. AMIA Annu Symp Proc 2010;2010:882-886 [FREE Full text] [Medline: 21347105]

55. Artificial Intelligence in Healthcare. London: Academy of Medical Royal Colleges; 2019.

56. Mesko B. The role of artificial intelligence in precision medicine. Expert Review of Precision Medicine and Drug Development 2017 Sep 20;2(5):239-241. [doi: 10.1080/23808993.2017.1380516]

57. Guo J, Li B. The Application of Medical Artificial Intelligence Technology in Rural Areas of Developing Countries. Health Equity 2018;2(1):174-181 [FREE Full text] [doi: 10.1089/heq.2018.0037] [Medline: $\underline{30283865}$ ]

58. Mullei K, Mudhune S, Wafula J, Masamo E, English M, Goodman C, et al. Attracting and retaining health workers in rural areas: investigating nurses' views on rural posts and policy interventions. BMC Health Serv Res 2010 Jul 02;10 Suppl 1:S1 [FREE Full text] [doi: 10.1186/1472-6963-10-S1-S1] [Medline: 20594367]

59. Guo P, Liu T, Zhang Q, Wang L, Xiao J, Zhang Q, et al. Developing a dengue forecast model using machine learning: A case study in China. PLoS Negl Trop Dis 2017 Oct;11(10):e0005973 [FREE Full text] [doi: 10.1371/journal.pntd.0005973] [Medline: 29036169]

60. Rodriguez-Ruiz A, Lång K, Gubern-Merida A, Broeders M, Gennaro G, Clauser P, et al. Stand-Alone Artificial Intelligence for Breast Cancer Detection in Mammography: Comparison With 101 Radiologists. J Natl Cancer Inst 2019 Mar 05:5. [doi: 10.1093/jnci/djy222] [Medline: $\underline{\text { 30834436] }}$

61. Houssami N, Kirkpatrick-Jones G, Noguchi N, Lee CI. Artificial Intelligence (AI) for the early detection of breast cancer: a scoping review to assess AI's potential in breast screening practice. Expert Rev Med Devices 2019 May;16(5):351-362. [doi: 10.1080/17434440.2019.1610387] [Medline: 30999781]

62. Escalante HJ, Montes-y-Gómez M, González JA, Gómez-Gil P, Altamirano L, Reyes CA, et al. Acute leukemia classification by ensemble particle swarm model selection. Artif Intell Med 2012 Jul;55(3):163-175. [doi: 10.1016/j.artmed.2012.03.005] [Medline: 22510477]

63. Sher P, Wong V, Shaw V, Hooley G, Loveridge R, Wilson D. Absorptive Capacity and Learning in Technology Transfer: The Case of Taiwanese Information Technology Firms. Internationalization 1998:105-121. [doi: 10.1007/978-1-349-26556-5 5]

64. Adepoju IOO, Albersen BJA, De Brouwere V, van Roosmalen J, Zweekhorst M. mHealth for Clinical Decision-Making in Sub-Saharan Africa: A Scoping Review. JMIR Mhealth Uhealth 2017 Mar 23;5(3):e38 [FREE Full text] [doi: 10.2196/mhealth.7185] [Medline: 28336504]

65. Vuong QH. The (ir)rational consideration of the cost of science in transition economies. Nat Hum Behav 2018 Jan;2(1):5. [doi: 10.1038/s41562-017-0281-4] [Medline: 30980055]

66. Mo Y, Kontonatsios G, Ananiadou S. Supporting systematic reviews using LDA-based document representations. Syst Rev 2015 Nov 26;4(1):172. [doi: 10.1186/s13643-015-0117-0] [Medline: 26612232]

\section{Abbreviations \\ AI: artificial intelligence \\ LDA: latent Dirichlet allocation \\ PCA: principal component analysis}


Edited by G Eysenbach; submitted 16.07.19; peer-reviewed by HP Do, $H$ Vuong; comments to author 14.08.19; revised version received 28.08.19; accepted 28.08.19; published 01.11.19

Please cite as:

Tran BX, Nghiem S, Sahin O, Vu TM, Ha GH, Vu GT, Pham HQ, Do HT, Latkin CA, Tam W, Ho CSH, Ho RCM

Modeling Research Topics for Artificial Intelligence Applications in Medicine: Latent Dirichlet Allocation Application Study

J Med Internet Res 2019;21(11):e15511

URL: https://www.jmir.org/2019/11/e15511

doi: $10.2196 / 15511$

PMID: $\underline{31682577}$

(CBach Xuan Tran, Son Nghiem, Oz Sahin, Tuan Manh Vu, Giang Hai Ha, Giang Thu Vu, Hai Quang Pham, Hoa Thi Do, Carl A Latkin, Wilson Tam, Cyrus S H Ho, Roger C M Ho. Originally published in the Journal of Medical Internet Research (http://www.jmir.org), 01.11.2019. This is an open-access article distributed under the terms of the Creative Commons Attribution License (https://creativecommons.org/licenses/by/4.0/), which permits unrestricted use, distribution, and reproduction in any medium, provided the original work, first published in the Journal of Medical Internet Research, is properly cited. The complete bibliographic information, a link to the original publication on http://www.jmir.org/, as well as this copyright and license information must be included. 